\title{
$\mathrm{PH} 9 \mathbf{1}_{\text {nanorama }}$
}

\section{Sociedad y patrimonio, el "apellido" de AR\&PA para todas sus ediciones futuras}

\begin{abstract}
Durante los días 10 al 13 de noviembre de 2016 se celebró en Valladolid la X edición de AR\&PA. El evento, fiel a una cita con el sector del patrimonio cultural que ha logrado mantenerse ininterrumpidamente desde hace casi veinte años, volvió a abrir sus puertas y a concitar el interés de instituciones, profesionales, estudiosos y ciudadanos, casi 20.000 personas interesadas por la cultura basada en el legado patrimonial. Destacan en esta edición la consolidación de la colaboración hispano-lusa y la convocatoria de la I Bienal Ibérica del Patrimonio Cultural en 2017 en Amarante.
\end{abstract}

Enrique Saiz Martín | Dirección General de Patrimonio Cultural, Consejería de Cultura y Turismo, Junta de Castilla y León

URL de la contribución <www.iaph.es/revistaph/index.php/revistaph/article/view/3884>

Esta Bienal ha contado con 247 entidades de dentro y fuera de España, 106 estands expositivos y se han desarrollado casi 200 actividades, de las que 180 fueron encuentros empresariales y reuniones profesionales.

AR\&PA, Bienal de la gestión y restauración del patrimonio cultural, ha ido evolucionando con actividades y secciones que completaban la tradicional oferta expositiva o de encuentro comercial y profesional que le dio origen. Así, por ejemplo, "AR\&PA Innovación" reúne proyectos e iniciativas resultado de las actividades de I+D+i en torno al patrimonio, algunas propuestas por jóvenes profesionales o investigadores a través de sus propios centros, o de spin off que pretenden abrirse camino en el campo comercial y de oferta de servicios.

Otro aspecto que viene caracterizando AR\&PA como proyecto y propuesta pública es su apuesta por la socialización de la cultura a través de los bienes del patrimonio, como una realidad capaz no solo de satisfacer su propia contribución al bienestar de las personas, las ciudades y los territorios, sino también como un factor clave en la propuesta de un nuevo modelo de gestión, más sostenible y eficiente, de los bienes patrimoniales.

En ese contexto AR\&PA asume a partir de ahora un "apellido" permanente para sus futuras ediciones: "sociedad y patrimonio". Entre sus secciones, "AR\&PA Iniciativas" destaca como escaparate y plataforma para la iniciativa social y para las actividades de distintos colectivos, pequeñas instituciones y aquellas ONG que actúan en bienes del patrimonio cultural.

Esta sección mostró y acogió el debate conjunto acerca de 23 proyectos: yacimientos olvidados; manifestaciones de etnografía local; o el descubrimiento y valorización de las huellas de la memoria judía en un territorio son algunos ejemplos. "AR\&PA en familia" volvió a acercar la realidad de los bienes y lugares del patrimonio al público más joven, convirtiendo la Bienal, especialmente durante el fin de semana, en un evento enormemente popular y concurrido.

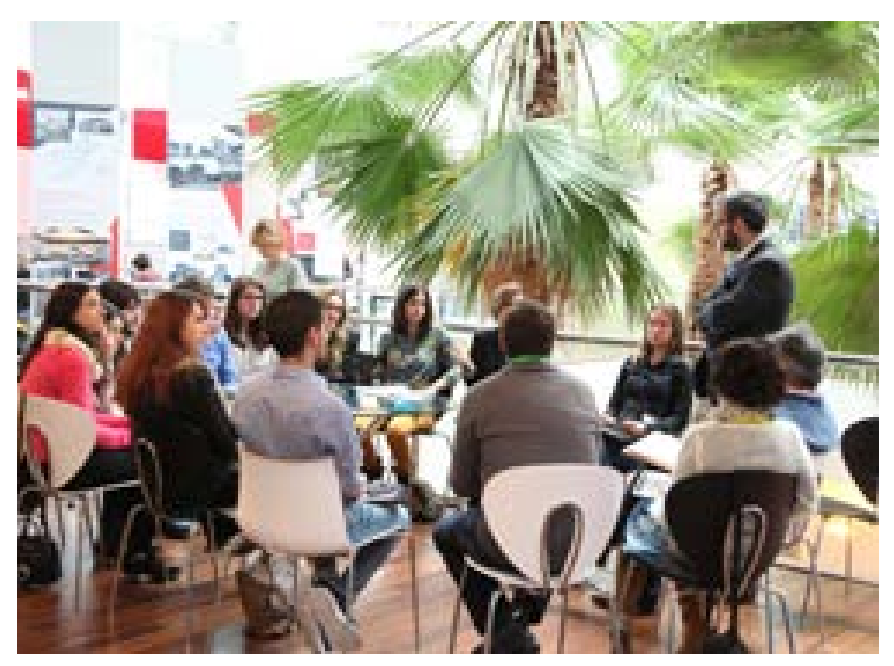

Encuentros profesionales. AR\&PA 2016 | foto Dirección General de Patrimonio Cultural. Junta de Castilla y León, de todas las imágenes que ilustran el texto 


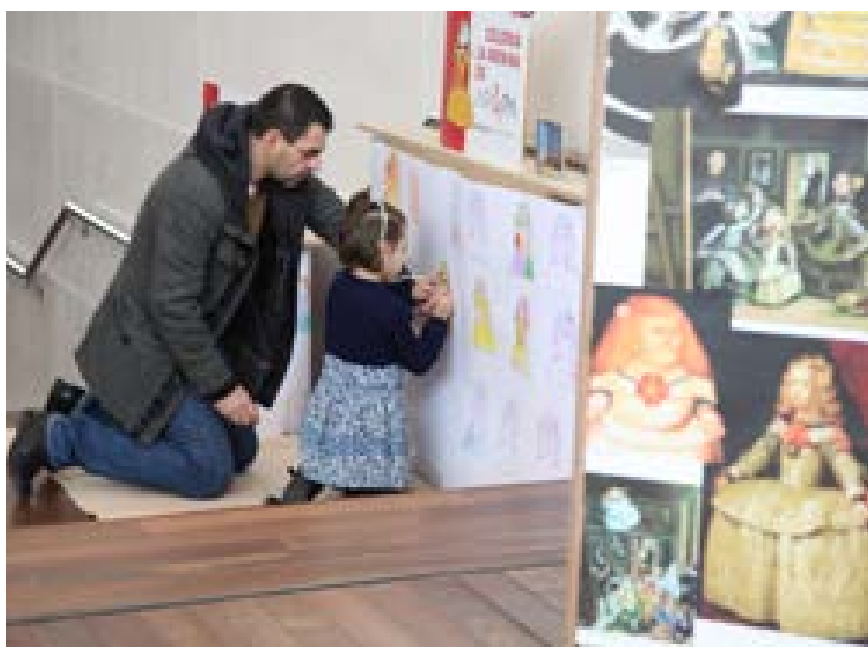

AR\&PA en Familia, 2016

Por su parte, "AR\&PA Empleo" reunió a escuelas-taller y centros de formación que buscan la incorporación al mercado laboral de jóvenes profesionales o en proceso de formación centrada en los trabajos de rehabilitación y restauración y en la gestión del patrimonio cultural.

AR\&PA 2016 presentó la Unidad de Gestión de Riesgos y Emergencias de Castilla y León. La UGRECYL se constituyó como grupo de trabajo encargado de asesorar, informar y colaborar con las personas que deben intervenir en las tareas de rescate y recuperación en situaciones de emergencias que pudieran afectar a los bienes culturales.

La apuesta científica se ha centrado siempre en la celebración del Congreso internacional AR\&PA que este año fue dirigido por Juan Carlos Prieto, Director de la Fundación Santa María la Real, y que focalizó su temática bajo la propuesta "patrimonio inteligente, territorios inteligentes".

Pero si algo ha caracterizado esta edición ha sido la fuerte e interesante participación del país invitado, Portugal, a partir de la presencia institucional coordinada por su Ministerio de Cultura, a cuyo frente se encontraba Paula Silva, Directora General de Patrimonio. A este impulso se unió el comercial y empresarial aglutinado por SPIRA, entidad lusa pionera en materia de comercialización de servicios en torno al patrimonio cultural.

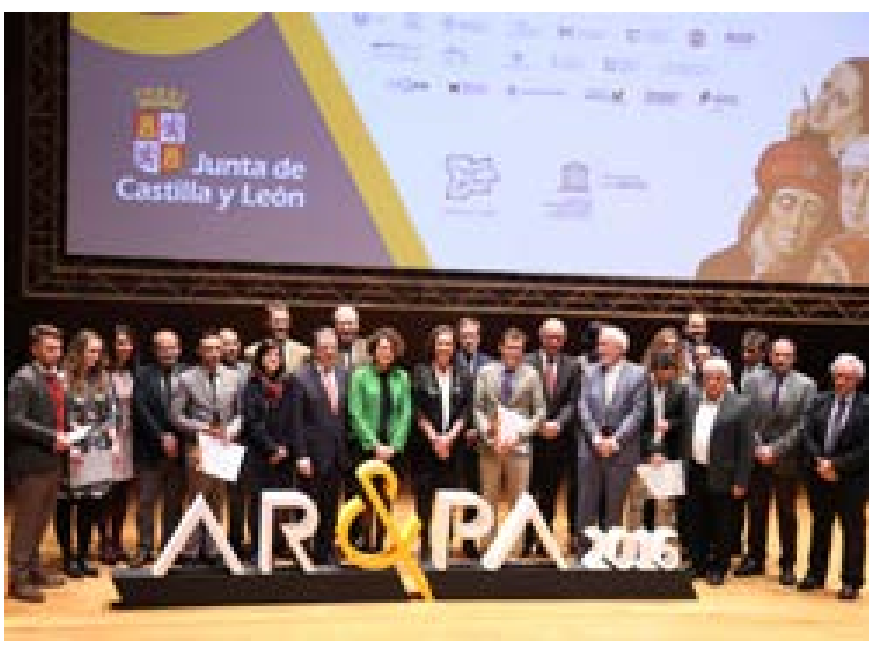

Gala de clausura y entrega de premios. AR\&PA 2016

Esta presencia permitió afianzar los contactos y oportunidades conjuntas, y cristalizó en una propuesta de partenariado para celebrar a partir de ahora una Bienal del patrimonio cultural con carácter ibérico organizada alternativa y anualmente por la Junta de Castilla y León y por SPIRA en colaboración con el ministerio portugués. Será AR\&PA Bienal Ibérica del patrimonio y su próxima edición tendrá lugar en Amarante en octubre de 2017.

En este contexto se enmarcó la presencia en AR\&PA de dos bienes portugueses incluidos en la lista de Patrimonio Mundial de UNESCO: el fado de Sara Paixao y el canto alentejano de Os Ganhões de Castro Verde. Ambos hicieron palpable la solidez de estas dos manifestaciones de la cultura musical y tradicional portuguesa.

AR\&PA Premios presentó en esta edición una importante novedad: el nuevo premio AR\&PA Joven entre estudiantes de arquitectura de todo el mundo, y al que se presentaron más de 70 proyectos de las universidades de Uruguay, Sevilla, Valladolid, Navarra, Madrid y Venecia. En cuanto al Premio Internacional AR\&PA, el jurado, presidido en esta ocasión por Martha Thorne, directora ejecutiva del Premio Pritzker de arquitectura, reconoció las buenas prácticas del proyecto portugués Val de Varosa, por proponer una gestión inteligente y sostenible de un amplio conjunto patrimonial en torno al Duero. 